\title{
Letters
}

\section{Graded exercise in chronic fatigue syndrome}

\section{Patients should have initial period of rest before gradual increase in activity}

EDITOR-We remain firmly opposed to exercise programmes that encourage patients with the chronic fatigue syndrome to increase their levels of physical activity progressively without making allowance for fluctuating levels of disablement. Nevertheless, we welcome Kathy Y Fulcher and Peter D White's finding that an individually tailored programme can produce benefits in a carefully selected subset. ${ }^{1}$ We have concerns, however, about the way in which these results have been oversimplified in the media and may now be put into practice by health professionals with no experience of this approach to management.

Our first concern is whether the results are as impressive as they seem. We find it surprising that patients in the exercise group who rated themselves as better showed no significantly greater improvement in either peak oxygen consumption or muscle strength than did the other patients. In addition, it would have been useful to know what percentage of both groups had stopped claiming long term sickness benefits-perhaps the most objective assessment of improvement.

Secondly, we are concerned that all the patients had been ill for a considerable period (median 2.7 years). Definitions of the chronic fatigue syndrome state that symptoms must have been present for at least six months before a diagnosis can be made. As a result no similar research study has been done into the most appropriate advice regarding rest and activity during the first few months of this illness. Until this has been done, our guidelines will continue to advise an initial period of rest followed by a gradual increase in activity.

Thirdly, severely affected patients were excluded from the study. A small but important minority are either wheelchair-bound or even bedbound, and for this group any type of activity programme must inevitably be structured at an entirely different level.

Fourthly, the authors seem to dismiss the possibility that fatigue could involve an underlying physiological or biochemical defect. Although considerable uncertainty surrounds the role of persistent viral infection and immunological dysfunction in the chronic fatigue syndrome, evidence links the condition with hypothalamic dysfunction, particularly hypocortisolaemia, ${ }^{2}$ and other disturbances of the central nervous system. ${ }^{3}$ Finally, in this heterogeneous disorder, the role of disordered oxidative metabolism in skeletal muscle cannot be ruled out as an explanation for fatigue in a subset of patients. ${ }^{4}$

\section{Charles Shepherd Medical director}

Anne Macintyre Medical adviser

ME Association, High Street, Stanford le Hope,

Essex SS17 0HA

1 Fulcher KY, White PD. Randomised controlled trial of graded exercise in patients with the chronic fatigue syndrome. BMJ 1997;314:1647-52. (7 June.)

2 Demitrack MA, Dale JK, Straus SE, Laue L, Listwak SJ, Kruesi MJP, et al. Evidence for impaired activation of the Kruesi MJP, et al. Evidence for impaired activation of the
hypothalamic-pituitary-adrenal axis in patients with hypothalamic-pituitary-adrenal axis in patients with
chronic fatigue syndrome. I Clin Endocrinol Metab 1991; 73:1224-34

3 Chaudhuri A, Majeed T, Dinan T, Behan PO. Chronic Chaudhuri A, Majeed T, Dinan T, Behan PO. Chronic
fatigue syndrome: a disorder of central cholinergic transmission. J Chronic Fatigue Syndrome 1997;3:3-16.

4 McCully KK, Natelson BH, Iotti S, Sisto S, Leigh JS. Reduced oxidative muscle metabolism in chronic fatigue syndrome. Muscle Nerve 1996;19:621-5.

\section{Including patients who rated themselves} as a little better would have altered results

EDITOR-"Editor's choice" in the issue of 7 June states, "we agree that myalgic encephalomyelitis (or chronic fatigue syndrome) is a serious condition" and "all conditions have a mental and physical component." This is the stance of the patient organisations supporting patients with this condition. Unfortunately, some doctors have trivialised this illness; ridiculed patients and their supporters; and subjected a few of them, including children, to oppressive, perhaps even abusive, forms of treatment. Hopefully, this is now a thing of the past. We need, as Harvey Marcovitch says, to explore what might be done to help them. ${ }^{1}$

In Kathy Y Fulcher and Peter D White's paper on graded exercise in adults, patients who rated themselves as very much better and much better were much more common in the exercise treated group than in the flexibility group (authors' table 1). ${ }^{2}$ If patients who rated themselves as a little better were also included, however, then the numbers were almost equal.

It should be made clear that the authors were treating a small subgroup of patients who were well enough to attend an outpatient department and free from sleep disturbance and recognisable psychiatric disorder. To most doctors dealing regularly with patients with the chronic fatigue syndrome, such patients are a small proportion, perhaps a tenth, of the total and would probably exclude most children. "Aerobic exercise" also needs defining if it is not to be confused with that form of exercise undertaken as a leisure activity. Fulcher and White's conclusion is important: graded exercise should be appropriately prescribed and not insisted on in all circumstances.

There are difficulties in producing hard facts in a condition like the chronic fatigue syndrome in children. Although Dowsett and Colby's study of schoolchildren ${ }^{3}$ has been criticised by Fiona Godlee because it was not rigorous and the children were not randomly selected, ${ }^{4}$ it should be regarded as a pilot study and "the art of the possible." The first difficulty is to find an acceptable definition of chronic fatigue in children because, for example, in many the onset is gradual $^{5}$; we need a better operational definition. Children form a special case because they are developing at the same time as the illness is developing and the diagnostic landmarks are not so well defined. Secondly, epidemiological studies of large populations cost a lot of money, and although Dowsett and Colby have not produced a rigorous study, they have given us a useful pointer and have done it on a shoestring.

Alan J Franklin Medical adviser, Action for ME/CFS Springfield Medical Centre, Springfield,

Chelmsford CM1 5TJ

1 Marcovitch H. Managing chronic fatigue syndrome in children. BMJ 1997;314:1635-6. (7 June.)

Fulcher KY, White PD. Randomised controlled trial of Fulcher KY, White PD. Randomised controlled trial of
graded exercise in patients with the chronic fatigue graded exercise in patients with the ch
syndrome. BMJ 1997;314:1647-52. (7 June.)

3 Dowsett E, Colby J. Long term sickness absence due to ME/CFS in UK schools: an epidemiological study with medical and educational implications. J Chronic Fatigue Syndrome 1997;3:29-42.

4 Godlee F. Plague or pure hype? BMJ 1997;314:1700 (7 June.)

5 Bell DS. Illness onset characteristics in children with chronic fatigue syndrome and idiopathic chronic fatigue J Chronic Fatigue Syndrome 1997;3:43-51.

\section{Patients were selected group}

EdiToR-Kathy Y Fulcher and Peter D White conclude that their findings support the use of graded aerobic exercise in the management of the chronic fatigue syndrome. ${ }^{1}$ Those readers who delve no further than the abstract and key points may welcome this "take home message." Several flaws in the paper, however, make accurate interpretation of the findings difficult and greatly limit its applicability. Firstly, less than two fifths of those screened for the trial actually entered it. Many of those who did not enter it were excluded on the basis of current psychiatric disorder, even though the Oxford criteria used by the authors do not specifically exclude patients with anxiety 
and depression. ${ }^{2}$ Given that this is already a subgroup selected by their referral to psychiatric outpatient departments, to select out those with a current psychiatric disorder makes them an unusual group indeed. Secondly, successful randomisation should make the intervention and control groups similar. Such comparability should enable the problem of confounders, known or unknown, to be accounted for. Evidence of the comparability of cases and controls should be presented. ${ }^{3}$ Age and sex are almost universal confounders. In this study one might also add body mass index, duration of illness, and even previous athletic training as other possible confounders. The paper does not break down the age and sex of the two groups to enable comparison. Thirdly, the main outcome measure is the self rated clinical global impression change score. This score is a validated measure of overall change. ${ }^{4}$ However, the validity of the subsequent categorisation of patients into those with a score of 1 or 2 and those with a score of 3-7, and whether this was a post hoc categorisation, is not stated. A categorisation into 1-3 (all scores representing an improvement) and 4-7 (the rest) would not have produced a significant change. Numerous other physiological outcome measures are provided, but more clinically relevant would have been consultation rates, use of drug treatment, and time off work (time off work was measured only at one year, after the crossover). In short, for those considering the options for managing this condition, especially those who commission services, the message should be that we need more information before we can tell if graded exercise will help most patients with the chronic fatigue syndrome.

Mike Sadler Consultant in public health medicine (primary care)

Portsmouth and South East Hampshire Health Authority, Portsmouth PO3 6DP

1 Fulcher KY, White PD. Randomised controlled trial of graded exercise in patients with the chronic fatigue syndrome. BMJ 1997;314:1647-52. (7 June.)

2 Sharpe MC, Archard LC, Banatvala JE, Borysiewicz LK,

2 Share AW, David A, et al. A report on chronic fatigue synClare AW, David A, et al. A report on chronic fatigue syn-
drome: guidelines for research. J R Soc Med 1991;84: drome:

3 Fowkes FG, Fulton PM. Critical appraisal of published research: introductory guidelines. BMJ 1991;302:1136-40. 4 Guy W. ECDEU assessment manual for psychopharmacology. Rockville, MD: National Institute of Mental Health, 1976:218-22.

\section{Chronic fatigue syndrome is heterogeneous condition}

EDITOR-The study reported by Kathy Y Fulcher and Peter D White will provide new hope to many patients diagnosed as having the chronic fatigue syndrome. ${ }^{1}$ Before exercise regimens become the treatment of choice, however, it is worth noting that over two fifths of the patients in the study reported no or little improvement. It is a pity that the researchers did not compare those who were "very much better" with those who were not, in terms of variables such as the onset of illness (acute or gradual, history of infection $)^{2}$ and the presence of additional symptoms frequently associated with the syndrome--for example, cognitive difficul- ties, nausea, and malaise after exercise. This might have shown whether one particular subgroup fared better than another, allowing doctors to tailor their advice and further improve patients' care. ${ }^{3}$

The possibility that subgroups may have different prognoses also deserves consideration. For instance, a recent study found that $70 \%$ of patients diagnosed as having epidemic neuromyasthenia recovered within two years. ${ }^{4}$ If two thirds of the subjects studied by Fulcher and White also had disease of acute onset linked to infection, one could argue that the exercise regimen reflected the natural course of the illness while the flexibility training made patients worse.

A final point concerns the 20 subjects taking full dose antidepressants. The authors do not specify why these drugs were being taken by people who did not have clinical depression or sleep disorders. Moreover, since many patients with the chronic fatigue syndrome cannot tolerate therapeutic doses of antidepressants, ${ }^{5}$ some of the reported fatigue and malaise may have been drug induced.

While treatments linked to behaviour seem to benefit many patients with chronic fatigue, further research is needed to characterise the minority in whom they do not. If studies fail to acknowledge the heterogeneity of the chronic fatigue syndrome, subgroups with different needs may be overlooked. ${ }^{2}$

Ellen M Goudsmit Editor, ME and CFS Medical Update

23 Melbourne Road, Teddington, Middlesex

TW11 9QX

1 Fulcher KY, White PD. Randomised controlled trial of graded exercise in patients with the chronic fatigue syndrome. BMJ 1997;314:1647-52. (7 June.)

2 Fukuda K, Straus S, Hickie I, Sharpe M, Dobbins JC, Komaroff A, et al. The chronic fatigue syndrome: a comprehensive approach to its definition and study. Ann comprehensive approach to
Intern Med 1994:121:953-9.

3 Lerner AM, Zervos M, Dworkin HJ, Chang CH, Fitzgerald JT, Goldstein J, et al. New cardiomyopathy: pilot study of $\mathrm{JT}$, Goldstein J, et al. New cardiomyopathy: pilot study of
intravenous ganciclovir in a subset of the chronic fatigue intravenous ganciclovir in a subset of the ch
syndrome. Infect Dis Clin Pract 1997;6:110-7.

4 Lyndrome. Infect Dis Clin Pract 1997;6:110-7. 4 Levine PH, Snow PG, Ranum BA, Paul C, Holmes MJ. Epi-
demic neuromyasthenia and chronic fatigue syndrome in West Otago, New Zealand: a 10-year follow-up. Arch Intern Med 1997;157:750-4.

5 Weir WRC. PVFS in an infectious diseases clinic. In: Jenkins R, Mowbray J, eds. Post-viral fatigue syndrome. Chichester: Wiley, 1991.

\section{Authors' reply}

Editor-We cannot tell Charles Shepherd and Anne Macintyre whether the treatment reduced the number of patients claiming benefits, but we did find that a significantly greater proportion had returned to work or study, compared to before treatment. An early return to activity or exercise after infections is probably beneficial rather than harmful, ${ }^{12}$ so rest is probably inappropriate advice, as long as fever has abated. We treat severely disabled patients in hospital using the same principle of appropriately prescribed exercise, agreed beforehand with the patient. The first "exercise" prescribed might be sitting up in bed for five minutes. We agree that aetiology is still uncertain in the chronic fatigue syndrome. However, McCully et al themselves suggested that
Patients' characteristics at baseline

\begin{tabular}{lccc} 
Characteristic & $\begin{array}{c}\text { Exercise } \\
\text { group }\end{array}$ & $\begin{array}{c}\text { Flexibility } \\
\text { group }\end{array}$ & $\begin{array}{c}\mathbf{P} \\
\text { value }\end{array}$ \\
\hline $\begin{array}{l}\text { Mean (SD) age } \\
\text { (years) }\end{array}$ & $37.9(9.3)$ & F36.6 (12.0) & 0.63 \\
$\begin{array}{l}\text { Mean (SD) body } \\
\text { mass index } \\
\left(\mathrm{kg} / \mathrm{m}^{2}\right)\end{array}$ & $23.9(5.1)$ & $23.7(4.1)$ & 0.87 \\
\hline No $(\%)$ of women & $23(70)$ & $26(79)$ & 0.89 \\
\hline No $(\%)$ of smokers & $5(15)$ & $6(18)$ & 0.98 \\
\hline $\begin{array}{l}\text { Mean (interquartile } \\
\text { range) duration } \\
\text { of illness (years) }\end{array}$ & $3.8(2.4-5.2)$ & $2.0(0.8-3.2)$ & 0.03 \\
\hline
\end{tabular}

Statistics used were independent $t$ tests, $\chi^{2}$ test, and Mann Whitney test.

reduced oxidative metabolism may be secondary to inactivity, ${ }^{3}$ while others have suggested that sleep disturbance may be the cause of hypocortisolaemia. ${ }^{4}$

We can reassure Allan J Franklin and Mike Sadler that we categorised "a little better" as a negative outcome before we collected any data, believing that this particular rating was not clinically important. We cannot agree that we treated an unusual or small subgroup of patients. All 167 screened patients were referred to a chronic fatigue clinic established 12 years ago. Two fifths of these patients were recruited into the trial. The commonest reason for exclusion was having a comorbid psychiatric disorder $(77 \%$ of those excluded), treatment of which usually led to resolution of fatigue, which suggests that the psychiatric disorder was the main cause of fatigue rather than the chronic fatigue syndrome itself. ${ }^{5}$

Ellen M Goudsmit can be reassured that neither a history of a triggering infection nor taking antidepressants affected the response to treatment. Antidepressants were being taken by 20 subjects to prevent a relapse of their previous comorbid depressive illness.

We agree with Sandler that randomisation should account for confounders, which is why we omitted the table (printed above) giving the data he requested, so that the paper was shorter, as requested by the journal. Analysis of covariance showed that longer duration of illness in the exercise group had no significant effect on outcome $(\beta=-0.10, t=-0.72, \mathrm{P}=0.47)$.

Peter D White Senior lecturer

Department of Psychological Medicine St Bartholomew's and the Royal London Medical and Dental School, London EC1A 7BE

Kathy Y Fulcher Laboratory director National Sports Medicine Institute, London EC1M 6BQ

1 Dalrymple W. Infectious mononucleosis. 2. Relation of bed rest and activity to prognosis. Postgrad Med 1964;35:345-9. 2 Repsher LH, Freehern RK. Effects of early and vigorous exercise on recovery from infectious hepatitis. NEngl J Med 1969;281:1393-6.

3 McCully KK, Natelson BH, Iotti S, Sisto S, Leigh JS Jr. Reduced oxidative muscle metabolism in chronic fatigue syndrome. Muscle Nerve 1996;19:621-5.

4 Leese G, Chattington P, Fraser W, Vora J, Edwards R, Williams G. Short-term night-shift working mimics the pituitary-adrenocortical dysunction in pituitary-adrenocortical dysfunction in chronic fatigu syndrome. J Clin Endocrinol Metab 1996;81:1867-70.

5 Lane TJ, Manu P, Matthews DA. Depression and somatization in the chronic fatigue syndrome. Am J Med
1991;91:335-44. 


\section{Chronic fatigue syndrome in children}

\section{Journal was wrong to criticise study in schoolchildren}

EDITOR-In his editorial on managing the chronic fatigue syndrome in children Harvey Marcovitch implies that a $37 \%$ response rate to our questionnaire about long term sickness absence in schools was poor and insufficiently explained, and he states that we overinterpreted the resulting data. $^{12}$

Detailed information on 333024 pupils and 27327 staff in 1098 schools cannot be so lightly dismissed. A balanced response from schools of different types and for different age ranges in widely spaced geographical locations made the rate of response unlikely to produce bias. The accuracy of case ascertainment in each district was easily checked by reference to variables in other diseases reported, such as leukaemia. Difficulties in obtaining responses were clearly explained as resulting from reorganisational demands on British schools concurrent with the study. Competition for funding produces additional pressures on corporate image, as also explained. Schools and local education authorities generally expressed reluctance to provide these statistics. A pilot study in private schools produced a response rate of only $27 \%$, even though details of illness did not differ from those in the public sector.

The study also made clear that schools were not involved in medical diagnosis, as suggested by Fiona Godlee. ${ }^{3}$ Schools have a legal duty to confirm the veracity of parents' explanations for long term sickness absence; all resulting documentation is confidential, and head teachers' professional probity in supplying accurate data must be respected.

Responsibility for any underdiagnosis or overdiagnosis uncovered by the study remains with the primary care doctor, who, in our experience, commonly consults hospital colleagues. In practice, comprehensive tables supplied with this study show little variability in case ascertainment between different local education authorities, with one exception. This authority, while recording the highest number of staff with myalgic encephalomyelitis or the chronic fatigue syndrome, reported only six pupils with the illness. Numbers with this diagnosis over the six districts ranged from 32 to 15 (SD.6.91) among staff and from 63 to 6 (14.43) among pupils; this variability suggests some element of bias peculiar to diagnosis in pupils, and not to us as authors of the study.

Arguments should not obscure the findings of the study. Pupils and staff in areas giving low levels of home tuition and a modified timetable were found to be more likely to withdraw from school entirely. Funding for microbiological studies of infections that seem to trigger the onset or relapse of myalgic encephalomyelitis or the chronic fatigue syndrome in schools would be well targeted.

E G Dowsett Honorary consultant microbiologist South Essex Health Trust, St Andrew's Hospital, Billericay, Essex CM12 0BH

Jane Colby Consultant for the education of children with myalgic encephalomyelitis

25 Dakyn Drive, Stock, Essex CM4 9TA

1 Marcovitch H. Managing chronic fatigue syndrome in children. BMJ 1997;314:1635-6. (7 June.)

2 Dowsett EG, Colby J. Long-term sickness absence due to ME/CFS in UK schools; an epidemiological study with medical and educational implications. J Chronic Fatigue Syndrome 1997;3:29-42.

3 Godlee F. Plague or pure hype? BMJ 1997;314:1700. (7 June.)

\section{Patient organisations are denied a voice}

EDITor-Action for ME is one of the two patient support groups referred to in "editor's choice" in the issue of 7 June. The organisation, which represents 8000 members, accepts that any illness can have both physical and psychological components. In fact, for the past five years it has offered psychological support in the form of professional telephone counselling, and our journal has carried numerous articles testifying to a more complex understanding than the editor implies.

What we have a problem with, however, is some medical journals' overemphasis on psychological factors when they refer to myalgic encephalomyelitis. Provocative features about hysteria and wandering wombs have not helped. ${ }^{1}$ Because of the possibility of cognitive malfunction, ${ }^{2}$ we believe that getting better is more complex that letting go of "symptom dependency" and "therapeutic nihilism"-terms that are frequently used in research attempting to show that abnormalities are not components of a primary pathological process but are secondary to behavioural aspects of myalgic encephalomyelitis, such as reduced physical activity.

One of the problems facing patient organisations is that the dialogue with the medical profession is conducted largely via the media. Through the ME Alliance, which represents four national charities involved with myalgic encephalomyelitis, we asked to be consulted during the preparation of the royal colleges' report; ; our request was ignored. Since publication of the report, our request for a meeting has been denied. Is it any wonder that we "use" the media in an attempt to have a voice? Action for ME's web page-http:/www.afme.org.uk - contains the ME Alliance's response to the royal colleges' report, and this response is available from Action for ME on request.

Gill Jacobs Director, Action for ME

7 Priory Road, Wells BA5 1SR

1 Richmond C. Myalgic encephalomyelitis, Princess Aurora, and the wandering womb. BMJ 1989;298:1295.

2 DeLuca J, Johnson SK, Ellis SP, Natelson BH. Cognitive functioning is impaired in patients with chronic fatigue syndrome devoid of psychiatric disease.J Neurol Neurosurg Psychiatry 1997;62:151

3 Joint Working Group of the Royal Colleges of Physicians, Psychiatrists, and General Practitioners. Chronic fatigue syndrome. London: RCP, 1996. (CR54.)
All studies must be subjected to rigorous scrutiny

EDITOR-Over the years, the ME Association has noted that some of those writing in the $B M J$ make assumptions about the views of organisations concerned with myalgic encephalomyelitis. These assumptions concern the organisations' views about the aetiology and treatment of the disease. We wish to put the record straight as regards the position of the ME Association. We do not regard the mind-body issue as clear cut. We accept that, as in any long term disabling illness, symptoms will include both physical and psychological components, and we make this clear in our literature. We find unacceptable the often voiced assumption that our views on aetiology and treatment are coloured by prejudice against psychological illness or a wish to stigmatise such illnesses as less valid than physical illness. All illness, whatever the cause, is legitimate, and patients with that illness are worthy of respect and acceptance.

Not all illnesses, however, share an aetiology, and not all illnesses respond to the same treatment. Both the report of a national task force ${ }^{1}$ and a report by the royal colleges $^{2}$ noted that a substantial minority of those patients presently grouped under the term "chronic fatigue syndrome" show no sign of past or present psychiatric disturbance. Clearly, in at least one subgroup of patients, psychiatric disturbance is not the primary cause of illness.

This being so, it seems to us that opinion formers such as the $B M J$ must ensure that all views and all scientific evidence be presented for evaluation. The ME Association has no objection to studies such as the recent survey of schools being subjected to rigorous scrutiny and, if necessary, vigorous criticism. ${ }^{3}$ This is part of the advancement of understanding. It must, however, apply to all studies presented, and our observations over the years have led us to believe that the $B M J$ has been guilty of a highly selective bias towards psychiatric studies, views, and editorials.

We hope that this selectivity will now stop. We also hope that, should the $B M J$ wish to comment on the ME Association or any other organisation, it will contact that organisation and ascertain its view rather than publish unsubstantiated assumptions.

Melanie Hume Chair

ME Association, High Street, Stanford le Hope, Essex SS17 0HA

1 National Task Force on Chronic Fatigue Syndrome (CFS), Post Viral Fatigue (PVFS), Myalgic Encephalomyelitis (ME). Report. Bristol: Westcare, 1994

2 Joint Working Group of the Royal Colleges of Physicians, Psychiatrists, and General Practitioners. Chronic fatigue syndrome. London: RCP, 1996. (CR54.)

3 Dowsett EG, Colby J. Long-term sickness absence due to ME/CFS in UK schools: an epidemiological study with medical and educational implications. I Chronic Fatigue Syndrome 1997;3:29-42.

\section{Special hospitals}

\section{Special hospitals are not prisons ...}

EDITOR-Clare Dyer reports on several important issues that are raised when patients discharged by psychiatrists commit 
a serious offence. ${ }^{1}$ In referring to the case of Mr Martin Mursell she seems to have confused the very different roles of prisons and special hospitals. Mr Mursell is reported to be "serving a life sentence in Rampton special hospital." Mr Mursell is a patient in Rampton Hospital under the Mental Health Act 1983. If he was convicted of murder and given a life sentence then he would have been transferred from prison to hospital under sections 47/49 of the Mental Health Act 1983 for treatment, but not to serve a life sentence. When such a patient no longer fulfils criteria for detention in hospital then he or she is returned to prison to serve the remainder of the sentence.

This point is more than one of mere semantics. Special hospitals are not prisons. They are maximum security psychiatric hospitals. The people receiving care and treatment within them are patients and not inmates, as they are at times called in the media.

It is important that the general public is not misinformed about the role of special hospitals by receiving wrong messages from the media. Patients admitted to special hospitals should not be unnecessarily stigmatised by the incorrect use of terminology which may have pejorative connotations. In this respect medical journals such as the $B M J$ have a vital role in using the correct terminology to serve as a model for the general media.

Jeremy Kenney-Herbert Consultant forensic psychiatrist

Reaside Clinic, Birmingham B45 9BE

Martin Humphreys Senior lecturer in forensic psychiatry

University of Birmingham, Birmingham

1 Dyer C. Psychiatrist resigns after second patient is charged with murder. BMJ 1997;314:1641. (7 June.)

*wave received three other letters making this point.-EDITOR

\section{... but have a history of problems}

EDITOR-In her editorial Elaine Murphy blames problems at special hospitals for mentally disordered offenders on the members of the Prison Officers' Association who staff the hospitals; she is not the first to do this. ${ }^{1}$ The association is an easy and often appropriate target, but it is not the whole problem. The Department of Health has known of problems in patient care in the special hospitals for 20 years (NHS Hospital Advisory Service on Broadmoor Hospital, unpublished data, 1975) but failed to make radical changes until 1989. No bureaucrat seems to have been blamed for this inertia. The isolation of staff and patients has long been recognised, yet the rest of the health service has not rushed to move patients out of the special hospitals. Instead it has been all too happy to have dangerous patients cared for elsewhere.

Current thinking is to move patients into enlarged, local, medium security units for long stay care. Local high security services have been mooted too. Calls for closure of the special hospitals neglect to address the realities of establishing these services where the "not in my back yard" mentality prevails. Money allocated in the 1970 s to medium security units was siphoned off; bed numbers grew painfully slowly. The movement of patients is dependent on local purchasers of health care who may find that there is an uncomfortable shortfall between the money attached to treating particular patients and the cost of local services. Economies of scale seem inevitable.

We should worry about repeating history. Forensic services alone build new institutions designed, as before, to deal with society's uncertainties about mentally disordered offenders. Local secure services may need to temper their entrepreneurial enthusiasm and ask themselves if they really can provide better care than their equally well intentioned predecessors. For instance, little psychotherapeutic skill exists in medium security units to deal with psychopaths (who are one third of the special hospital population). Attention should be given to whether the beneficial aspects of special hospitalskitchen gardens, on site education, work experience in bricklaying, and social events - can be created in local secure settings. Long stay patients in medium security units will spend little time, if any, off site; their quality of life is important.

Vigilance will be required if and when patients are moved into local medium security units. Patients will face risks similar to those they face now; these stem from long length of stay, few community contacts, intractable problems, and the dangers of therapeutic nihilism. They will also face new risks from living on mixed wards. The existence of the Prevention of Professional Abuse Network, a charity that helps patients cope with abuse by therapists, and the long history of inquiries into non-forensic hospitals $^{2}$ indicates that members of the Prison Officers' Association have no monopoly on inadequate patient care.

Annie Bartlett Senior lecturer and consultant in forensic psychiatry

St George's Hospital Medical School, London SW17 0RE

1 Murphy E. The future of Britain's high security hospitals. BMJ 1997;314:1292-3. (3 May.)

2 Martin L. Hospitals in trouble. Oxford: Blackwell, 1984.

\section{Summative assessment compounds workload for MRCGP examination}

EDITOR-My colleagues and I are among the first group of general practice registrars who have to pass the new compulsory summative assessment.

Although we are all enthusiastic about general practice and understand that assessment is needed to produce well trained general practitioners of suitable competence, the current situation seems somewhat unacceptable. Most of us aim to take the MRCGP examination in our final six months of training in general practice. The additional compulsory requirement to complete a summative assessment at the same time has unnecessarily increased our workload, especially as there is considerable overlap between the two examinations: the summative assessment seems to be a common denominator in both. The production of video work for the doctor-patient consultations requires typed assessment of each consultation. Unfortunately, summative assessment requires a different format for typed work from that required for the MRCGP examination. If done properly, the work is likely to take many weeks. This not only means that less time can be spent revising for the MRCGP examination but, more importantly, the enjoyment of general practice training is lost and vital follow up of patients is sacrificed. Implications may go further. I am sure the current situation is not attractive to junior doctors undecided on their future career.

The current situation needs to be revised. At least, if video work is good enough to pass the MRCGP examination it ought to be of sufficient standard to satisfy summative assessment and avoid the need to produce separate work.

T P Cunliffe Senior house officer

Accident and Emergency Departent, North Tees Hospital, Stockton TS19 8PE

\section{Inequality in funding for AIDS across England threatens regional services}

EDITOR-Recent developments in antiretroviral treatment offer the potential for substantial progress in the management of patients infected with HIV. ${ }^{1}$ A series of trials have now shown that combination treatments with antiretroviral drugs offer significantly better prospects to patients than the use of monotreatment with nucleoside analogues such as zidovudine. ${ }^{2}$ In addition, limited evidence suggests that triple treatments, incorporating protease inhibitors, produce further substantial reductions in viral loads and may almost entirely eliminate the virus. ${ }^{3}$ Monotreatments have proved too costly for many countries, and double or triple treatments are likely to cost around two and four times as much respectively. ${ }^{4}$ Previously, in England the cost of HIV treatment has not been considered prohibitive. The current method of allocating HIV treatment and care funds, however, means that some regions of England are substantially better equipped than others to finance these new treatments. Using the latest data from the national database for monitoring area of residence of patients with HIV infection (the national survey of prevalent diagnosed HIV infections, 1995), ${ }^{5}$ we have calculated the funding allocated (for 1997-8) to each region per resident with HIV related disease or AIDS. The funding differs nearly threefold between the most and least favourably funded regions (figure ${ }^{1}$ ).

Currently, treatment and care funds for HIV infected patients are allocated to regions according to the number of patients with AIDS who were first reported by health 


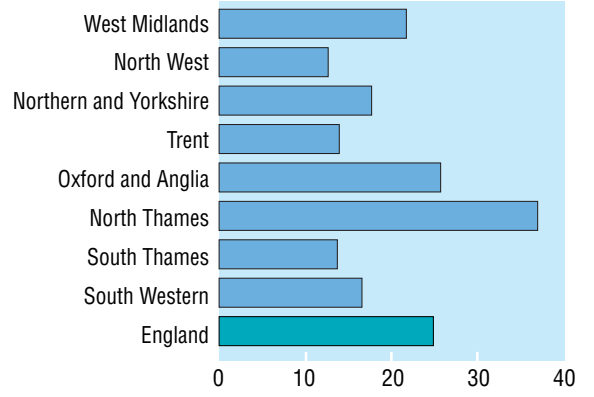

$£ 1000 /$ patient with HIV related disease or AIDS

Funding allocation for treatment and care in AIDS and HIV infection for 1997-8, calculated per person with HIV related disease or AIDS resident in each region

services in that region and have not yet been reported to have died. This method takes no account of patients who change treatment centre after the diagnosis, even though such information is available. ${ }^{5}$ Equally, the method ignores the substantial treatment costs arising from new treatments are associated with conditions that occur before AIDS develops.

Irrespective of where an HIV infection is diagnosed, most patients now seek treatment within their region of residence $(86 \%) .^{5}$ The current unequal distribution of treatment funding means that costly but potentially beneficial treatments such as triple treatments may only be available, or at least be more readily available, in those regions receiving disproportionate funding. Only an expeditious move to a more appropriate and equitable funding formula will prevent substantial inequalities in treatment, a movement of patients towards better funded areas, and possibly the collapse of high quality treatment centres in poorly funded regions.

Mark A Bellis Senior lecturer

Joanne McCullagh Research associate

Sexual Health and Environmental Epidemiology

Unit, Department of Public Health, University of

Liverpool, Liverpool L69 3GB

Roderick Thomson Public health projects coordinator

Sefton Health Authority, Liverpool L22 0QB

David Regan Public health specialist

Manchester Health Authority, Manchester M60 7PL

Qutub Syed Regional epidemiologist

Communicable Disease Surveillance Centre (North West), Public Health Laboratory, Liverpool L9 7AL

Terry Kelly Joint commissioning manager, substance misuse

Liverpool Health Authority, Liverpool L3 6AL

1 Dillner L. HIV may be eliminated from reservoirs of infection in the body. BMJ 1997;314:1436. (17 May)

2 BHIVA Guidelines Co-ordinating Committee. British HIV Association guidelines for antiretroviral treatment of HIV seropositive individual. Lancet 1997;349:1086-92.

3 Cavert W, Notermans DW, Staskus K, Wietgrete SW, Zupancic M, Gebhard K, et al. Kinetics of response in lymphoid tissues to antiretroviral therapy of HIV-1 infection. Science 1997;276:960-4.

4 Alcorn K. The cost of treatment. nam-AIDS Treatment Update 1996;47:4-5.

5 Molesworth A. Results from the 1995 survey of prevalent clinically diagnosed HIV infections in England, Wales, and clinically diagnosed HIV infections in England, Wales, and Northern
R77-82.

\section{New combined hepatitis A and $B$ vaccine}

EDITOR-Recently a new combined hepatitis $A$ and $B$ vaccine has been introduced (Twinrix; SmithKline Beecham) and widely promoted in the lay press for travellers to insanitary regions of the world, often with little or no regard for the duration of travel. We believe that the use of vaccines by travellers should be evidence based, in this case based on evidence of infection in returning travellers.

Over the past 12 months this regional infectious disease unit has admitted five patients, all of Asian origin, with acute hepatitis $\mathrm{B}$, all probably secondary to an injection received abroad in circumstances which suggested that there was no indication for parenteral medication. ${ }^{1}$ Inquires have revealed that injections are preferred within Asian ethnic minorities because they are perceived as stronger than oral preparations. Nationally, 614 cases of acute hepatitis B were reported between 50th week 1995 and 50th week 1996 to the Communicable Disease Surveillance Centre at Colindale. ${ }^{2}$ Information on risk factors was available in 335 cases: nine were thought to have been acquired parenterally abroad, four from a transfusion, three from injections, and two from dialysis. Sexual intercourse is known to be the other major route of transmission, but cases with this attribution were not subdivided according to country of acquisition.

Awareness of the risks of injections and adherence to safe sexual practices is much more important than immunisation for most travellers, in preventing transmission not only of hepatitis B but also of HIV and hepatitis $\mathrm{C}$, for which no vaccine is available. Overemphasis on vaccination may obscure this message and could lead to a false sense of security. We are liaising with the locally based Asian Health Forum to try to ensure that travellers in this group are aware of the importance of ensuring that necessary injections are given with a sterile needle.

Vaccination against hepatitis B should be reserved for the small group of travellers spending more than a month in a highly endemic areas such as the Far East and central Africa, who are more likely to require medical intervention in accordance with current Department of Health guidelines. ${ }^{3}$ This group is also more likely to be in a position to plan to receive immunisation six months before travelling.

Martin Dedicoat Specialist registrar

Christopher J Ellis Consultant physician

Department of Infection and Tropical Medicine, Birmingham Heartlands Hospital, Birmingham B9 5SS

martded@AOL.com

1 Dedicoat M, Ellis C, Abid M, Boxall E. Iatrogenic hepatitis $\mathrm{B}$ in Travellers [abstract]. Transcripts $R$ Soc Tropical Med Hygiene (in press).

2 [Reports of cases of hepatitis B.] Commun Dis Rep CDR Wkly 1996;6(No 3-No 51).

3 Salisbury D, Begg N. Immunisation against infectious disease. Salisbury D, Begg N. Im

\section{Requesting necropsies}

\section{Health care must be both evidence based} and humanity based

EDITOR-Jane Turner and Beverley Raphael missed several opportunities in their editorial on requesting necropsies and breaking other bad news. ${ }^{1}$

Firstly, they missed the opportunity to move away from the tendency of experts to lead from the rear, exhorting the troops at the front line to do more and do it better. It ought to be a principle that at least one coauthor of such editorials should work in a specialty targeted for advice and have day to day involvement in requesting necropsies.

Secondly, they missed the opportunity to criticise the notion of the necropsy as "the final audit" and to reinforce the point that these procedures are no more error free than any other process of gathering information. There is too little scientific evidence on the reliability, sensitivity, and specificity of necropsy data to permit this view to remain unchallenged.

Thirdly, they failed to recognise that changing the attitudes of doctors requires more than mere instruction. Medical students' attitudes change-and not always for the better-during their training, but the process is gradual and is little affected by formal educational courses. Behaviour patterns can, however, be modified, and the first step is to make it clear that clinical examinations will include marks for empathic interpersonal communication.

Fourthly, and most importantly, the authors failed to acknowledge the importance of the structural context of acute health care. The realities of breaking bad news are that this often has to be done out of hours, during emergencies, and by tired and pressurised junior doctors. Comfortable interview suites may not be available, and other, seriously ill but living, patients may require attention. However, relatives should not have to wait until a senior doctor, whom they may not recognise as having been involved in the patient's care, is hauled in to break the news. Sharing their distress with the doctors and other staff intimately involved in the patient's final hours may be of greater value.

Finally, the authors missed the opportunity to scotch the false dichotomy between biological sophistication on the one hand and "humanity and awareness of suffering" on the other. Surely it is time to acknowledge that the two are by no means mutually exclusive and that health care must be both evidence based and humanity based.

Teifion Davies Senior lecturer in community psychiatry

Division of Psychiatry and Psychology, UMDS, St Thomas's Hospital, London SE1 7EH

Turner J, Raphael B. Requesting necropsies. BMJ 1997; 314:1499-500. (24 May.) 


\section{General practitioners should be taught} relevant skills during vocational training

EDitoR-I agree with Jane Turner and Beverly Raphael that humanity and awareness of suffering are required when requesting necropsies. ${ }^{1}$ The authors discuss the issues raised by hospital requests for necropsy and do not deal with the more complex issues relating to general practice. About a fifth of deaths are followed by necropsies, and three quarters of these are requested by coroners for legal and not medical reasons. ${ }^{2}$ General practitioners complete $30 \%$ of death certificates themselves $^{3}$ and refer deaths for a necropsy via the coroner. However, only $12 \%$ of deaths in general practice are referred to the coroner, compared with $18 \%$ of deaths in hospital (unpublished data, 1996). One hospital study showed that a large number of relatives were distressed by requests for necropsy. ${ }^{4}$ The commonest deterrent to general practitioners requesting necropsies is the distress that may be caused to the relatives of the person who has died. Often the first point of contact for the relatives at the time of death is their general practitioner, who not only certifies the death but also supports them. The relatives may often be patients of the general practitioner, and it would therefore be inappropriate to request a routine necropsy during this visit. Requesting a necropsy may even have a detrimental effect on the doctor-patient relationship that has been developed over years. Relatives accept, albeit with reluctance, the need to refer a patient to the coroner for legal reasons and to establish the cause of death. The authors conclude that clinicians' skills in requesting permission for necropsies need to be improved during medical training. Although general practitioners have skills in breaking bad news, they lack skills in requesting permission for necropsies. Skills learnt during hospital training and as an undergraduate are not appropriate for general practice and could instead be addressed during vocational training for general practice.

Kamlesh Khunti Clinical lecturer

Faculty of Medicine, University of Leicester,

Leicester General Hospital, Leicester LE5 4PW

1 Turner J, Raphael B. Requesting necropsies. BMJ 1997; 314:1499-500. (24 May)

2 Berlin A, Wagstaff R, Bhopal R, Spencer J. Postmortem examinations: general practitioners' knowledge, behaviour, and attitudes. BMJ 1994;308:1080-1.

3 Black DA, Jachuck SJ. Death certification in general practice: review of records. BMJ 1984;288:1127-9.

4 Start RD, Sherwood SJ, Kent G, Angel CA. Audit study of next of kin's satisfaction with clinical necropsy service. $B M$ J 1996;312:1516.

\section{Necropsy rate was increased to $21 \%$ in one hospital}

Editor-We agree with Jane Turner and Beverley Raphael's editorial on requesting necropsies. ${ }^{1}$ In the United States a necropsy rate of $15 \%$ is required of all institutions involved in general internal medicine residency programmes accredited by the Accreditation Council for Graduate Medical Education. In July 1994 our medical service necropsy rate fell to $8 \%$ for the fiscal year. To
Necropsy rate for department of medicine for

fiscal year 1996. Figures are numbers

(percentages) of deaths in which necropsy was carried out

\begin{tabular}{lcc} 
Month & $\begin{array}{c}\text { No of } \\
\text { deaths }\end{array}$ & $\begin{array}{c}\text { No (\%) of } \\
\text { necropsies }\end{array}$ \\
\hline Oct 1995 & 26 & $4(15)$ \\
\hline Nov 1995 & 16 & $4(25)$ \\
\hline Dec 1995 & 20 & $7(35)$ \\
\hline Jan 1996 & 18 & $2(11)$ \\
\hline Feb 1996 & 26 & $7(27)$ \\
\hline Mar 1996 & 20 & $4(20)$ \\
\hline Apr 1996 & 20 & $6(30)$ \\
\hline May 1996 & 17 & $3(18)$ \\
\hline Jun 1996 & 13 & 0 \\
\hline Jul 1996 & 18 & $6(33)$ \\
\hline Aug 1996 & 14 & $3(21)$ \\
\hline Sep 1996 & 16 & $1(6)$ \\
\hline Fiscal year 1996 & 224 & $47(21)$ \\
\hline
\end{tabular}

improve our figures we formed a necropsy quality improvement team, which meets monthly. The team (composed of clinicians, administrative staff, and pathologists) follows trends and devises ways to improve the process of obtaining necropsies.

Each day, a necropsy assistant informs us of the names of patients who died the preceding day and the names of the junior house staff involved in their care. We then call the doctor as soon as possible to ask what, if any, problems he or she had in obtaining the necropsy. We ask how the request for permission was framed and make suggestions if appropriate. We praise the effort, whether or not permission was granted.

We agree with the editorial that continuing medical education in developing skills for requesting necropsies is preferable to the "one off package" of training that most junior doctors receive. ${ }^{1}$ A synopsis of the critical elements for success in obtaining a necropsy is constantly reinforced (including the importance of the doctor's attitude when confronting the patient's family (necropsy should be viewed positively and requested in every death); sensitive timing of the request; and the availability of the attending doctor to both the family and junior doctors to discuss any issues pertaining to the death; and that necropsy is of possible benefit for others (through education and research) and may absolve guilt concerning the death). ${ }^{2}$

Each week we have a joint necropsy conference for staff working in internal medicine and pathology. All members of the junior house staff, pathology trainees, and medical and pathology attendings are invited. A medical resident who was involved in the patient's care presents the clinical aspects of the case, and the pathology residents discuss the salient points arising from the necropsy. The chiefs of medicine and pathology then summarise the important teaching points. We always congratulate the resident who obtained the permission for necropsy at the end of the conference.

The necropsy is a key tool in the understanding of human disease. We have managed to increase our necropsy rate to
$21 \%$ (in the fiscal year 1996 (table)), and to $25 \%$ in the past eight months. Constant reinforcement seems to be the key in keeping the necropsy rate above $15 \%$. We are aiming for $25 \%$.

Glenn Matfin Attending physician

Harold M Adelman Professor of internal medicine Willard S Harris Chief, medical service James A Haley Veterans' Hospital, 13000 Bruce B Downs (111), Tampa, FL 33612, USA

1 Turner J, Raphael B. Requesting necropsies. BMJ 1997;314:1499-500. (24 May.)

2 McManus BM, Wood SM. The autopsy: simple thoughts about the public needs and how to address them. Am J Clin Pathol 1996;106(suppl 1):S11-4.

\section{The future of healthcare systems}

\section{Many questions about reform of health sector remain unanswered}

EDITOR-The NHS has been in a state of exceptional change for almost 10 years, and these political changes in the structure of the service will continue if the contents of a recent executive letter from the NHS Executive are to be heeded. ${ }^{1}$ Richard Smith's editorial on the future of healthcare systems highlights the need to move the debate forward to a non-political phase, which must include the re-engineering of the whole health system. ${ }^{2}$ The move from industrial age medicine to information age health care described by Jennings et al is fundamental to this process. ${ }^{3}$ Information technology and health knowledge systems must be at the heart of these changes. Differentiation of highly specific clinical information from generalisable knowledge for healthcare workers will become more important. Systems will need to be produced to manage both human resources and appropriate developments in technology; changes should not be driven purely by technological fashion.

Other issues in this re-engineering process include the changing roles of health professionals. Fundamental questions on interdisciplinary team working need to be asked. Nurse clinicians are now taking over a considerable volume of work from the doctors they are replacing. Who will be responsible for clinical care in this setting? Work traditionally carried out by doctors is increasingly being done by nurses; what role will doctors have in information age health care?

New methods of clinical working are being introduced into the NHS. Evidence based medicine, integrated care pathways, and clinical protocols are beginning to have an impact on the quality of health care. What preparation should we give our students to work in these new ways? How will experienced clinicians cope with these changes to clinical practice?

The concept of a primary care led NHS highlights the importance of primary care in the new NHS. What will be the role of general practitioners, and what training will be required to meet the new demands of a 
re-engineered primary care service? Will patients accept these changes to the NHS?

The current debate about reform of the health sector leaves many questions unanswered. For the process to continue it is essential that the new government moves rapidly through its political agenda for the NHS, leaving a robust platform on which to build the information age healthcare system that Britain deserves.

Peter Bundred Senior lecturer in primary care University of Liverpool, Liverpool L69 3GB

lain Buchan Research fellow

Medical lnformatics Unit, University of Cambridge, Cambridge

1 NHS Executive. Changing the internal market.Leeds: NHSE, 1997. (EL(97)3.)

Smith R. The future of healthcare systems. $B M J$ 1997;314:1495-6. (24 May.)

3 Jennings K, Miller K, Materna S. Changing health care. Santa Monica, CA: Knowledge Exchange, 1997.

\section{Rigid managed care programmes should never replace systems that allow flexibility}

EDITOR-Several future scenarios facing health service planners throughout the developed world were well described and assessed in Richard Smith's editorial. ${ }^{1}$ It seems, though, as if the entire group at the meeting that Smith reports fell into the same trap, one that tempts so many of us at the end of the 20th century. All the analyses made the implicit assumption that health care is a quantifiable commodity and that its users are nothing more than human machines, whose responses are as predictable and transparent as those of a motor car being serviced.

This reductionist biotechnical approach to medicine denies the fact that people, unlike machines, are influenced by several social and psychological factors and that the connection between intervention and outcome is often difficult to make. So far, we have been able to connect outcomes with surgical interventions fairly well (replaced hips generally allow patients to walk further, more easily); with some drug treatments (diabetic patients do better when taking insulin); and with a few psychological inputs (a positive mental attitude to cancer seems to improve survival).

Most of medicine, however, is concerned more with caring for patients than with curing them of their mechanical problems, and any health system that does not acknowledge this fact will never have its optimal impact on the health of its population. This probably means that the rigid, protocol driven managed care programmes, or the algorithmic disease management schedules, should never replace systems that allow enough flexibility for the therapeutic relationship to work constructively. The principles that underlie any successful system should include:

- making the patient (not the illness) the focus of care

- encouraging ongoing (as opposed to episodic) relationships between therapist and client
- using evidence based interventions when

these are available and appropriate

- allowing flexibility in approach when this

is not contraindicated

- encouraging well informed consumption

of services

- keeping control of any intervention away

from those who have a vested interest in it

- rewarding providers of care for the outcomes of their activity, rather than for its processes.

Once these principles are applied, the specific funding mechanisms become almost irrelevant. There are obviously political and cultural issues at play, and any system will need to take them into account, but these are subtexts of the main arguments.

Finally, it may be worth remembering Voltaire's chastening aphorism on the nature of health care generally: "The art of medicine is to keep the patient entertained whilst nature takes its course."

Jonathan Shapiro Senior fellow

Health Services Management Centre, University of Birmingham, Birmingham

J.A.Shapiro@bham.ac.uk

1 Smith R. The future of healthcare systems. BMJ 1997; 314:1495-6. (24 May.)

\section{Method for rigorously assessing cost} effectiveness of new drugs must be set up

EDITOR-In his editorial on the future of healthcare systems Richard Smith concluded that health care would be transformed over the next 20 years. ${ }^{1}$ We would like to see changes to the criteria for licensing new drugs in Britain, and modifications to the way new drugs are introduced into the NHS. We think that in this instance the balance between the need to promote innovation and ensuring the most cost effective use of public money is wrong.

We are concerned that the introduction of new expensive drugs of uncertain clinical benefit distorts the development of local services away from areas of greatest need. Recent examples of this include $\beta$ interferon 1-a for multiple sclerosis, riluzole for amyotrophic lateral sclerosis, and donepezil for Alzheimer's disease. These drugs have been licensed while there are serious doubts about their efficacy:

How large is the health gain achieved?

How relevant is it clinically and to the patient?

How precise is the estimate of the benefit?

For all of these drugs, concerns have been expressed about the appropriateness of the outcomes used in the studies, the size and valuation of the benefits, and the confidence in the precision of these estimates because of small numbers. Currently, new drugs have to be shown to be safe and have some chance of being effective. We would like to see the drug licensing agencies (the European Medicines Evaluation Agency and the Medicines Control Agency) adopt the rigorous standards of critical appraisal of clinical effectiveness that the Department of Health urges NHS clinicians, trusts, and health authorities to adopt. ${ }^{2}$ This would mean raising their threshold for clinical effectiveness so that drugs are not launched prematurely.

A related problem is "delicensing." This currently occurs only if a drug is shown to be unacceptably harmful rather than ineffective or nearly so. Without more active delicensing, new drugs may have to meet more stringent criteria than existing drugs. Technological developments will make today's new drugs tomorrow's poor performers.

We believe that direct action by the Department of Health and the NHS could resolve these unsatisfactory arrangements. We would like to see them add new drugs to the list of those that cannot be prescribed on the NHS because of lack of good quality evidence on cost effectiveness. This would entail setting up a method for assessing the cost effectiveness of new drugs with the rigour used by the Cochrane Collaboration. Such a new system would have to link with the current method for agreeing tariffs with the pharmaceutical industry for drugs prescribed in the NHS.

Philip Milner Professor of public health School of Postgraduate Medicine, University of Bath, Bath BA2 7AY

K Walshe Senior lecturer

Health Services Management Centre, Birmingham University, Birmingham B15 2RT

Graham Wynyard Medical director NHS Executive

A Lipp Consultant in public health medicine

East Norfolk Health Authority, Norfolk NR7 0HT

R Milne Visiting senior lecturer

Wessex Institute for Health Research and Development, Winchester SO22 5DH

Smith R. The future of healthcare systems. $B M /$ 1997;314:1495-6. (24 May.)

NHS Executive. Improving the effectiveness of clinical services. Leeds: NHSE, 1996. (EL (96) 110.)

**We were unable to include details of the report of the meeting in the editorial. The Globalization of Managed Care, the final report of the Andersen Consulting Health Futures Forum held in Singapore on 19-21 March 1997, is available from Andersen Consulting; contact Lawrence M Gee, One Market Plaza, Spear Street Tower, Suite 3700, San Francisco, CA 94105, USA (phone +1 415537 5596; lawrence.m. gee.@ac.com).-Editor

\section{Deaths from cervical cancer began falling before screening programmes were established}

EDITOR-The contrasting viewpoints in the letters from C Mary Anderson and Amanda Herbert illustrate the dilemma of cervical screening $^{12}$ : abnormal results are common, but the disease we are trying to prevent was rare before screening. ${ }^{3}$ Do the high rates of detection exist because we are averting a new epidemic of 7000 cases, ${ }^{2}$ or even 7000 deaths, ${ }^{4}$ each year in England? Or do the vast majority of lesions represent an early and reversible stage in the pathogenesis of cancer? 


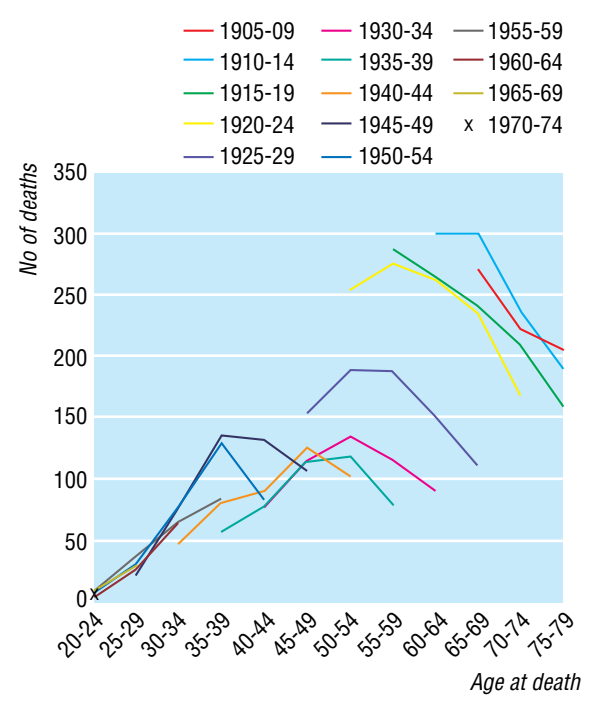

Number of deaths from cancer of the cervix (ICD 180 ) in 1975, 1980, 1985, 1990, and 1995 in England and Wales in five year birth cohorts. Deaths among women aged over 80 are not included in the figure (Source: Office for National Statistics)

Screening has been available in Britain since the mid-1960s, but it was not until call and recall programmes were widely established in the late 1980s that appreciable numbers of women aged over 35 were screened. The "epidemic" used to explain the high treatment rates must therefore be confined to women born since 1930. The figure shows the number of deaths from cervical cancer since 1975 by year of birth in five year cohorts. These data do not give precise rates of deaths from cervical cancer. They do, however, show the actual number of deaths. A fall in the number of deaths from cervical cancer occurred in each successive cohort this century. This trend predated screening. (Data from 1950, available from the Office for National Statistics, show no real alteration to the figure.)

Deaths in cohorts born after 1930 flatten off at an earlier age; this gives a strong indication of the effect of screening. ${ }^{5}$ An implausibly drastic change in cervical cancer has to be postulated if an additional 7000 deaths, or 7000 cases of life threatening disease, are being averted each year. Such an epidemic would have been manifest as a steep rise in death rates in health districts that were slower to organise screening programmes and in those groups of women who chose not to be screened. There is no evidence for this. It may be that deaths from cervical cancer in women born since 1930 are being halved by screening. If so, then the number of deaths in 1995 would have been 2000 in the absence of screening instead of 1339 (which would represent a doubling of the observed 661 deaths in women born since 1930). This saving of hundreds of lives comes at a high cost. Department of Health statistics show that in England and Wales each year about 800000 women have abnormal smears; 166000 of these abnormalities are severe enough to warrant referral for investigation and treatment. A tiny minority of these women are actually helped.

The NHS cervical screening programme is among the best in the world, and 30 years' experience has shown much about the inherent complexities and limitations of early detection as an approach to preventing cancer. It is easy to make simplistic claims about screening. In the long term we will do more for the public by being honest.

A E Raffle Consultant in public health medicine Avon Health Authority, Bristol BS2 8EE

1 Anderson CM. Cervical screening. BMJ 1997;314:1277. (26 April.)

2 Herbert A. Cervical screening. BMJ 1997;314:1277-8. (26 April.)

3 Raffle AE, Mackenzie EFD, Alden B. Detection rates for abnormal cervical smears: what are we screening for? Lancet 1995

4 Johnson J. Media focus on failures of screening 4 Johnson J. Media focus on failures

programme. BMJ 1997;314:1630. (31 May.) Sasieni PD, Cuzick J, Farmery E. Accelerated decline in cervical cancer mortality in England and Wales. Lancet $1995 ; 346: 1566-7$

\section{Doctors should beware of asking for too high a salary}

EDITOR-The poor pay of doctors in the 1960s has been redressed owing to the efforts of the BMA and because society recognised our worth. Now I think that the profession should beware of asking too much.

Recently, a friend of mine took on a new partner in general practice. In his first year he was paid more than I got after 20 years as a consultant general surgeon. Now his salary is between $£ 90000$ and $£ 100000$ a yearnot bad for someone who is barely 30 . Admittedly, the practice is extremely well run and not typical of other practices; but if this man was getting half of the salary he would be doing very well indeed.

No doctor in employment is poor. A stable society depends on there not being too large a gap between the rich and the poor. Do we as a profession really wish to be seen by society in the same light as accountants and lawyers?

Richard Baker Retired consultant surgeon 20 Island Bank Road, Inverness IV2 4QS

\section{$B M J$ apologises to cats everywhere}

Seep 957

EDITOR-Liam Farrell writes graphically about his brutal killing of a fox which he had crippled by deliberately driving over it. ${ }^{1} \mathrm{He}$ seems to feel regret but no remorse for this act. Indeed, he invites our admiration: for his willingness to discharge the responsibilities he carries by virtue of his closeness to nature (pause for purple prose) and for his understanding of the wider issues raised by his behaviour (pause for second rate philosophising about euthanasia).

We wondered if we had missed the point. Was hitting the animal really accidental? If so, why the deceit? Black humour? An obscure attempt at irony? We decided not. The article isn't remotely funny, and Farrell is too self regarding to be ironical. If the story is true we must conclude that its author is wilfully cruel to animals and insensitive to the feelings of people who might be affected by his actions. These are unappealing characteristics, and distressing to find in a doctor.

The Views and Reviews section is meant to be provocative, but we found this article deeply offensive. It is not right that space should be given to people to parade their vices in this self indulgent and confrontational manner. Our view is that it would do the $B M J$ no harm to seek a replacement contributor forthwith.

Alison House General practitioner

Allan House Senior lecturer in psychiatry

5 Shaftesbury Avenue, Leeds LS8 1DR

1 Farrell L An encounter with Reynard. BMJ 1997;315:686. (13 September.)

**We have received over 50 letters complaining about Liam Farrell's piece and one letter supporting his dislike of cats. This is almost as many letters as we received when we got Mozart's birthday wrong and advocated an elaborate treatment for weaver fish stings when they can actually be treated with any warm fluid, including urine. The $B M J$ is not anticat (we have even debated getting an office cat), and we apologise to cats everywhere and to readers who were distressed by Liam's piece. He is a writer who might be called a "magical realist," and we hoped that readers would not take his writing literally. When the nursery rhyme describes cows jumping over the moon and dishes running away with spoons, neither cows nor dishes are intended to follow the advice. Similarly we implore readers not to squash cats.EDITOR

\section{Advice to authors}

We receive more letters than we can publish:we can currently accept only about one third. We prefer short letters that relate to articles published within the past four weeks. We also publish some "out of the blue"letters, which usually relate to matters of public policy.

When deciding which letters to publish we favour originality, assertions supported by data or by citation, and a clear prose style. Letters should have fewer than 400 words (please give a word count) and no more than five references (including one to the BMJ article to which they relate); references should be in the Vancouver style. We welcome pictures.

Letters, whether typed or sent by email, should give each author's current appointment and full address. Letters sent by email should give a telephone and fax number when possible. We encourage you to declare any conflict of interest. Please send a stamped addressed envelope if you would like to know whether your letter has been accepted or rejected.

We may post some letters submitted to us on the world wide web before we decide on publication in the paper version. We will assume that correspondents consent to this unless they specifically say no.

Letters will be edited and may be shortened. 